\author{
Bronek M Boszczyk \\ Michael Bierschneider \\ Stefan Hauck \\ Rudolf Beisse \\ Michael Potulski \\ Hans Jaksche
}

\section{Transcostovertebral kyphoplasty of the mid and high thoracic spine}

Received: 4 October 2004

Revised: 21 January 2005

Accepted: 31 March 2005

Published online: 21 June 2005

(C) Springer-Verlag 2005
B. M Boszczyk $\cdot$ M. Bierschneider H. Jaksche

Neurosurgery, Berufsgenossenschaftliche Unfallklinik Murnau, Murnau, Germany

S. Hauck $\cdot$ R. Beisse $\cdot$ M. Potulski Trauma Surgery, Berufsgenossenschaftliche Unfallklinik Murnau, Murnau, Germany

B. M Boszczyk ( $\square)$

University of Berne, Inselspital, Spine Service, Bern, Switzerland

E-mail: B.Boszczyk@gmx.net

\begin{abstract}
While Kyphoplasty is increasingly becoming a recognised minimally invasive treatment option for osteoporotic vertebral fractures and neoplastic vertebral collapse, the experience in the treatment of vertebrae of the mid (T5-8)- and high (T1-4) thoracic levels is limited. The slender pedicle morphology restricts the transpedicular approach at these levels, necessitating extrapedicular placement techniques. Fifty five vertebrae of 32 consecutive patients were treated with kyphoplasty at levels ranging from T2-T8 for vertebral fractures (27 patients) or osteolytic collapse (5 patients). All procedures were performed through the transcostovertebral approach under fluoroscopic guidance. The radioanatomical landmarks of this minimally invasive approach were consistently identified and strictly adhered to. One fracture required open instrumentation due to posterior column injury in addition to kyphoplasty. Identification of specific radioanatomical landmarks allowed precise tool introduction in all
\end{abstract}

cases without intraspinal or paravertebral malplacement. Average operating time for patients with osteoporotic fractures was $30 \mathrm{~min}$ per level (range 13-60 $\mathrm{min}$ ) and $52 \mathrm{~min}$ per level (range 35-95 $\mathrm{min}$ ) in neoplastic cases. Biopsy yield in patients with known or suspected malignancies was 100\%. Epidural cement leakage was detected in one patient with pedicular osteolysis. Perforation of the lateral vertebral cortex during balloon inflation occurred in another patient. Both intraoperative complications were without clinical significance. Kyphoplasty in mid- to -high thoracic levels is possible via the transcostovertebral route under fluoroscopic guidance. Strict adherence to a stepwise protocol of tool introduction following defined radioanatomical landmarks is mandatory for the safe completion of this minimally invasive technique.

Keywords Kyphoplasty · Minimally invasive surgery - Thoracic spine · Vertebral compression fracture

\section{Introduction}

As fractures of the upper thoracic spine are comparatively rare [2, 10], the experience with $\mathrm{KP}$ in vertebrae above T8 is limited. Published KP case numbers range from 11 levels in 97 patients (T5-T8) [8] to 8 levels in 30 patients (T6-T8). For neoplastic lesions $4 \mathrm{KP}$ procedures out of 56 patients (T3-T8) [5] have recently been published. Some more extensive KP studies unfortunately do not provide a detailed breakdown of the vertebral levels treated [6, 12]. Experience in vertebroplasty (VP) is greater $[4,7]$, however this is not directly comparable to $\mathrm{KP}$ in which larger cannulas are used and stronger convergence is required for optimal balloon expansion. 
The purpose of this report is to present our operative experience of 55 transcostovertebral KP procedures in mid (T8-T5) and high (T4 and above) thoracic vertebrae.

\section{Material and methods}

\section{Patient collective}

Thirty-two consecutive patients (19 female, 7 male; average age 69 years, range 49 - 90) with vertebral fractures of the thoracic spine of $\mathrm{T} 8$ and above were treated with KP for osteoporotic fractures (27 patients), osteolytic collapse (5 patients) or high velocity fractures (1 patient) (Table 1). In total 55 vertebrae were augmented with PMMA (Table 1). The highest level treated was T2. The osteolytic lesions were due to plasmocy- toma $(n=1)$, metastasis of cervix carcinoma $(n=1)$, breast carcinoma $(n=2)$ and gastric carcinoma $(n=1)$. All patients with neoplastic collapse had disseminated disease or were not considered to be suitable candidates for extended operative resection and reconstruction. In the patient with the high velocity fracture of T3, classified as type B2.3 according to the scheme by Magerl et al. [10], internal fixation with a pedicle screw system was combined with KP. No vertebra of the collective had lost more than $2 / 3$ of the original height, as judged from the preoperative computed tomography $(\mathrm{CT})$ or plain radiograph. Two of the patients $(2$ and 13 in Table 1) required an additional procedure for new thoracic fractures. As these operations were completely independent of the first, they were treated as separate cases for the purpose of operative data collection in this investigation.

Table 1 Epidemiological data and operative time

\begin{tabular}{|c|c|c|c|c|c|}
\hline Patient & Sex & Age & Vertebrae & Av. or time per level & Diagnosis \\
\hline 1 & $\mathrm{~F}$ & 74 & $\mathrm{~T} 7, \mathrm{~T} 8$ & 13 & Osteoporosis \\
\hline 2 & M & 90 & $\mathrm{~T} 8,(\mathrm{~T} 11)$ & 25 & Osteoporosis \\
\hline 4 & $\mathrm{~F}$ & 75 & T6,T7 & 40 & Osteoporosis \\
\hline 5 & $\mathrm{~F}$ & 72 & T6,T7,Т8(T9-11) & 18 & Osteoporosis \\
\hline 6 & $\mathrm{~F}$ & 79 & $\mathrm{~T} 7,(\mathrm{~T} 11)$ & 38 & Osteoporosis \\
\hline 7 & $\mathrm{~F}$ & 79 & T6,T7,(Т9) & 30 & Osteoporosis \\
\hline 10 & $\mathrm{~F}$ & 54 & $\mathrm{~T} 5, \mathrm{~T} 6$ & 35 & Breast-CA metastasis \\
\hline 11 & M & 64 & Т5,T6,T7,Т8,(T9-11) & 30 & Osteoporosis \\
\hline 12 & $\mathrm{~F}$ & 62 & T8 & 26 & Breast-CA metastasis \\
\hline 13 & $\mathrm{~F}$ & 69 & $\mathrm{~T} 8$ & 27 & Osteoporosis \\
\hline 14 & $\mathrm{~F}$ & 69 & T6,T7,(T11) & 30 & Osteoporosis \\
\hline 15 & M & 54 & $\mathrm{~T} 4$ & 50 & Osteoporosis \\
\hline 21 & $\mathrm{~F}$ & 80 & T6,T7 & 15 & Osteoporosis \\
\hline 22 & $\mathrm{~F}$ & 80 & $\mathrm{~T} 7$ & 20 & Osteoporosis \\
\hline 23 & M & 66 & T6(T10,T12) & 40 & Osteoporosis \\
\hline 24 & $\mathrm{~F}$ & 79 & $\mathrm{~T} 5, \mathrm{~T} 6, \mathrm{~T} 7$ & 33 & Osteoporosis \\
\hline 25 & $\mathrm{~F}$ & 69 & T6 & 45 & Osteoporosis \\
\hline 26 & M & 58 & T7(L1-L3) & 24 & Osteoporosis \\
\hline 27 & $\mathrm{~F}$ & 60 & T3 & 120 & High velocity injury \\
\hline 28 & $\mathrm{~F}$ & 78 & T8,(T9) & 40 & Osteoporosis \\
\hline 29 & M & 59 & $\mathrm{~T} 4, \mathrm{~T} 5, \mathrm{~T} 6$ & 23 & Osteoporosis \\
\hline 30 & $\mathrm{~F}$ & 74 & T7,T8,(L5) & 20 & Osteoporosis \\
\hline 31 & $\mathrm{~F}$ & 68 & T8 & 40 & Osteoporosis \\
\hline 32 & $\mathrm{~F}$ & 64 & $\mathrm{~T} 6, \mathrm{~T} 7, \mathrm{~T} 8$ & 23 & Osteoporosis \\
\hline 33 & M & 75 & $\mathrm{~T} 7$ & 30 & Osteoporosis \\
\hline
\end{tabular}

All vertebrae of a patient treated in the same operative session are listed with the levels below T8 included in brackets. Average operative time per level in minutes was obtained by dividing the total operative time by the number of vertebrae treated. Where applicable, the underlying malignancy is included. Patient 27 was treated with additional internal fixation due to an unstable traumatic fracture type B2.3. Patient pairs 2 and 3, and 13 and 14 respectively are the same person, but are treated as separate cases as they were treated for different fractures on completely separate occasions. 
Fig. 1 Drawing of the transcostovertebral placement of the bone biopsy needle with the tip just penetrating the lateral pedicle at its base. In the view from posterior (a) the needle passes above of the transverse process and meets the pedicle at the craniolateral circumference. The lateral view (b) confirms the placement of the tip of the needle close to the base of the pedicle. In an axial view (c) the needle is seen to pass through the costovertebral gap, between the neck of the rib and the lateral pedicle circumference, towards the base of the pedicle

All operations were performed in the operating theatre under general anaesthesia. With the exception of the patient with additional internal fixation, all procedures were completed percutaneously under biplanar fluoroscopy. An unilateral approach, propagated by Brugieres et al. [1] in 1990 as the "transcostovertebral" technique and now generally known as the extra- or parapedicular approach [14], was used for the placement of a single $15 \mathrm{~mm} \mathrm{KP}$ balloon in all but three large T7 vertebral bodies that could contain two balloons. The side of the approach was chosen according to fracture morphology and whenever possible with the trajectory of the approach directed away from the mediastinal vessels.

The data concerning the operative technique and radiological assessment is presented here, whereas midlongterm clinical and radiological outcome will be reported at a later stage within a more extensive patient collective dealing with KP outcome in general. Pre- and immediate postoperative radiographic assessment included measurement of posterior and anterior vertebral body height, as well as segmental kyphosis (measured between the endplates of the fractured vertebra) in the lateral radiograph, or sagittal CT reconstruction when available. Average values and standard deviations were calculated for the osteoporotic cases, whereas averages and the respective range of values were determined for the smaller neoplastic group.

\section{Operative technique of transcostovertebral KP}

The patient is positioned prone on cushions and the affected vertebral body is localised with biplanar fluoroscopy. The anterior-posterior (ap) view is adjusted with the spinous process of the targeted vertebral body in the exact midline, endplates parallel and pedicles placed symmetrically in the upper lateral quadrant of the projection of the vertebral body. The lateral (lat) view is adjusted with pedicles superimposed, endplates parallel and the posterior wall aligned with a single contour. After draping, the costal angle associated with the targeted vertebral body is localised in the ap view and a transverse stab incision is placed immediately superior to its cranial border. A bone biopsy needle is

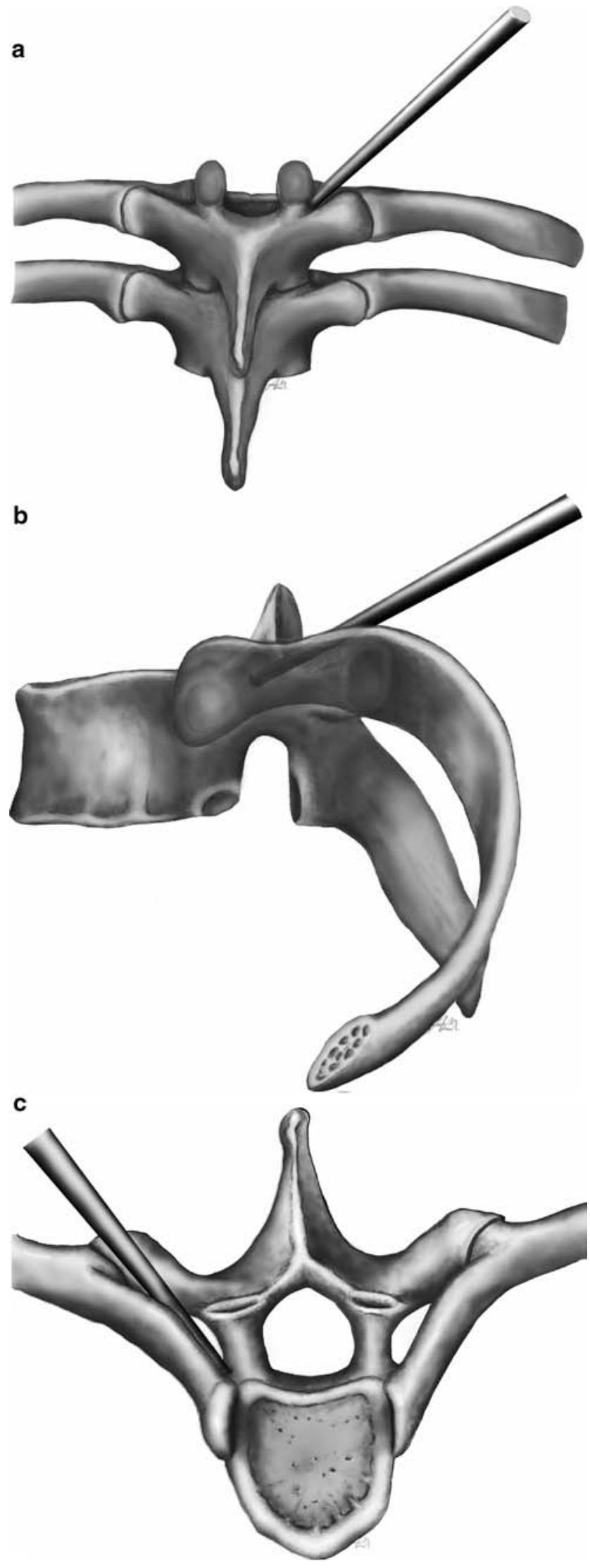


Fig. 2 Axial drawing of a single kyphoplasty balloon placed convergently through the transcostovertebral approach

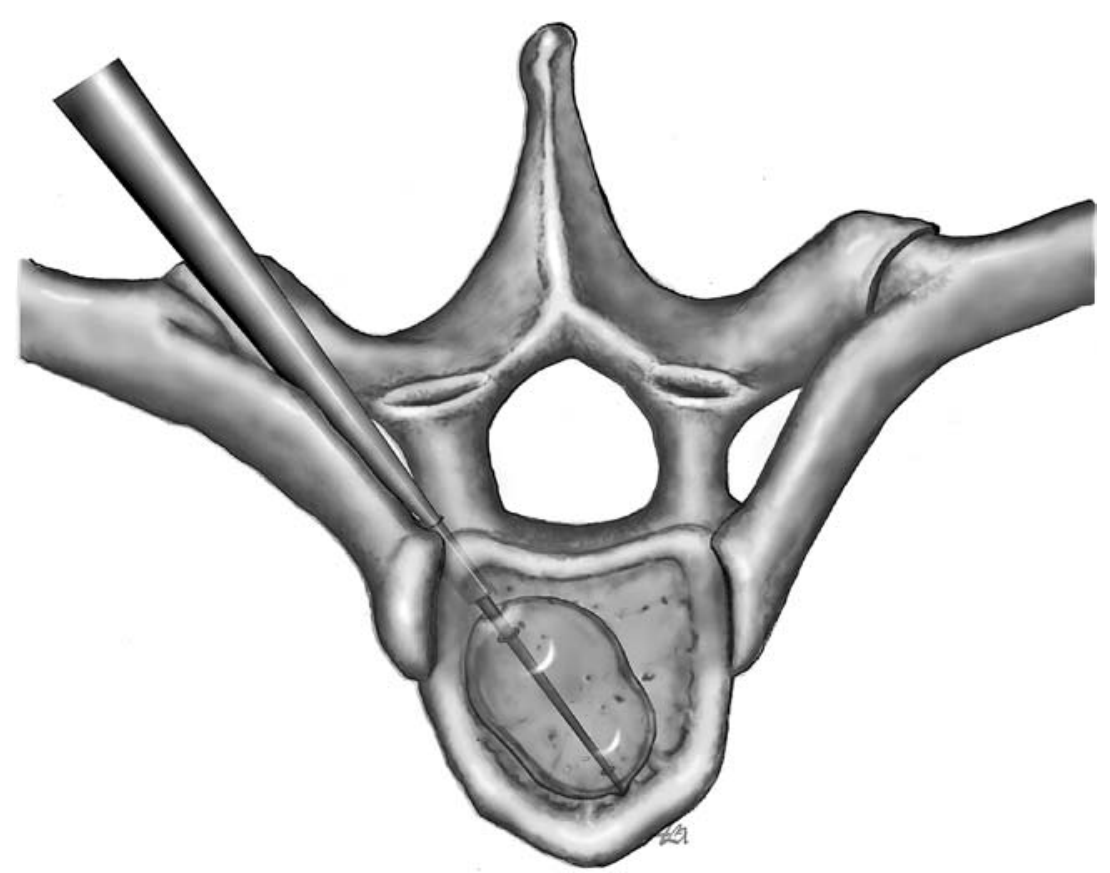

introduced from craniolateral towards the costovertebral joint. Contact is made with the neck of the rib or the transverse process. Ideally, the needle is then slid along the neck of the rib, passes under the transverse process and through the ligament complex of the costovertebral joint until the lateral pedicle wall is reached (Fig. 1a-c). In the fluoroscopic ap view, the projection of the tip of the needle should be at the craniolateral circumference of the targeted pedicle. In the corresponding lat view, the tip of the needle should be projected between the superior and inferior border of the pedicle, anterior to the facet joints and close to the base of the pedicle. A projection of the tip of the needle posterior to the facet joint indicates placement on the transverse process and requires repositioning to pass under the transverse process along the neck of the rib. Once the needle is correctly placed (Fig. 1), it is tapped through the lateral pedicle cortex. The tip of the needle should be verified within the pedicle ring on the ap view before passing the posterior vertebral wall in the lat view. Only after having passed the posterior vertebral wall on the lat view may the tip of the needle cross the medial pedicle wall in the ap view. Strict adherence to these landmarks is mandatory for the avoidance of spinal perforation.

From this operative step on, the KP procedure is almost identical to previous descriptions of the technique in the lumbar and lower thoracic spine $[6,14]$. The only difference being the use of a single, centrally placed balloon (Fig. 2) in the smaller upper thoracic vertebrae.

\section{Results}

Operative findings

In severe osteoporosis or coexisting spinal deformity, it was not always possible to identify the details of all radioanatomical landmarks (pedicle rings, endplates and spinous process). Symmetrical placement of each pedicle ring in the upper lateral quadrant in the ap view proved to be the most reliable landmark for midline orientation. The spinous process was found to occasionally deviate from the longitudinal axis despite symmetrical pedicle orientation. The ap projection of the vertebral endplates was often considerably distorted due to the kyphotic deformity of the vertebral body, impeding flush fluoroscopic alignment. It was found that ap alignment of the anterior endplate contour to superimpose the pedicle rings was most reliable for obtaining a tool trajectory into the vertebral body without perforation of the endplates. The levels from T5 to T8 generally did not pose difficulties with regard to identification of the lat radiological landmarks (superimposed pedicles and endplates as well as posterior vertebral wall alignment). In the upper levels (T2-T4) the lat view of the pedicles and posterior vertebral wall was frequently obscured due to superimposition of the shoulder girdle. At these levels, the ap projection of the tool in relation to the pedicle ring was the key feature in preventing spinal perforation by keeping the 
tool lateral to the projection of the medial pedicle wall until the vertebral body had clearly been reached in the lat view.
In neoplastic lesions, the landmarks were occasionally indistinct due to osteolytic lesions. In these vertebrae alignment was obtained according to the remaining

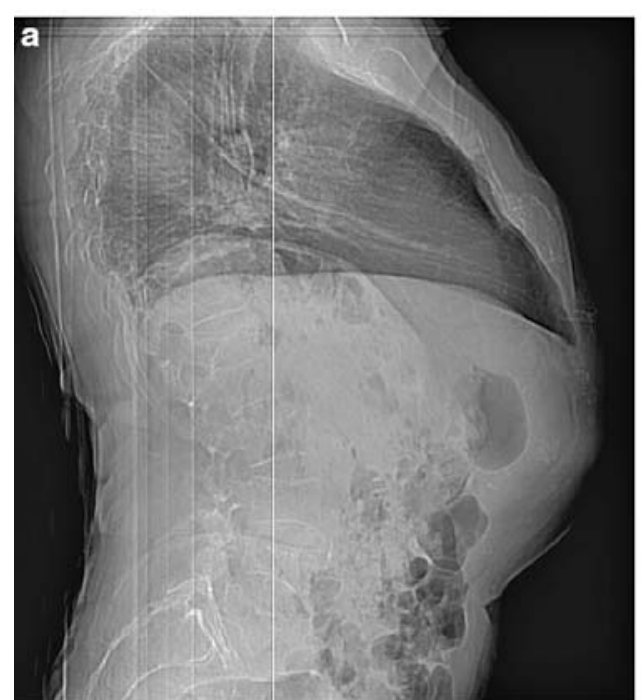

d
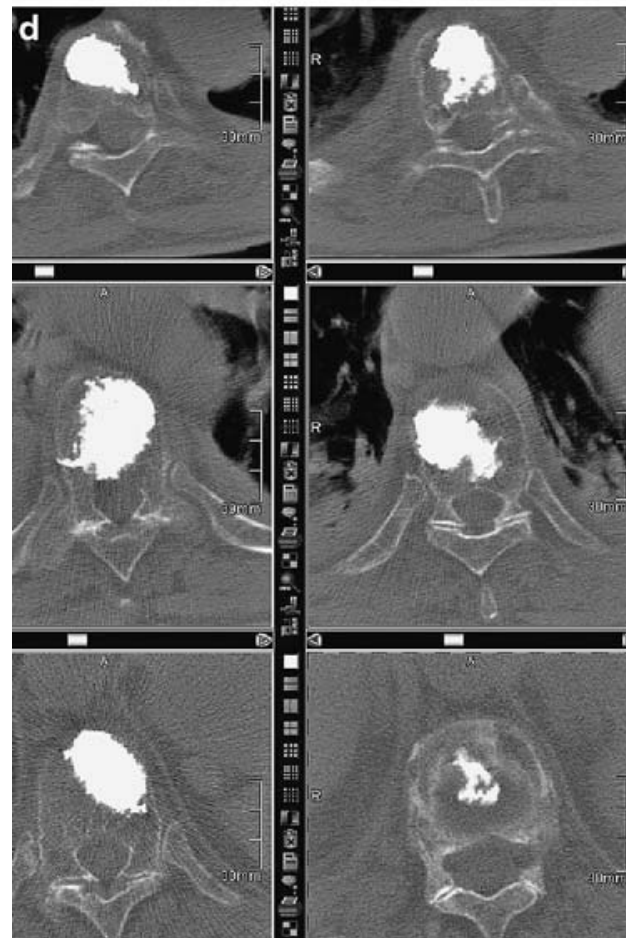

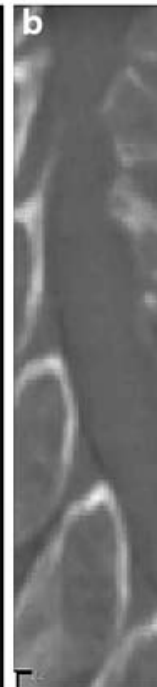

mation c
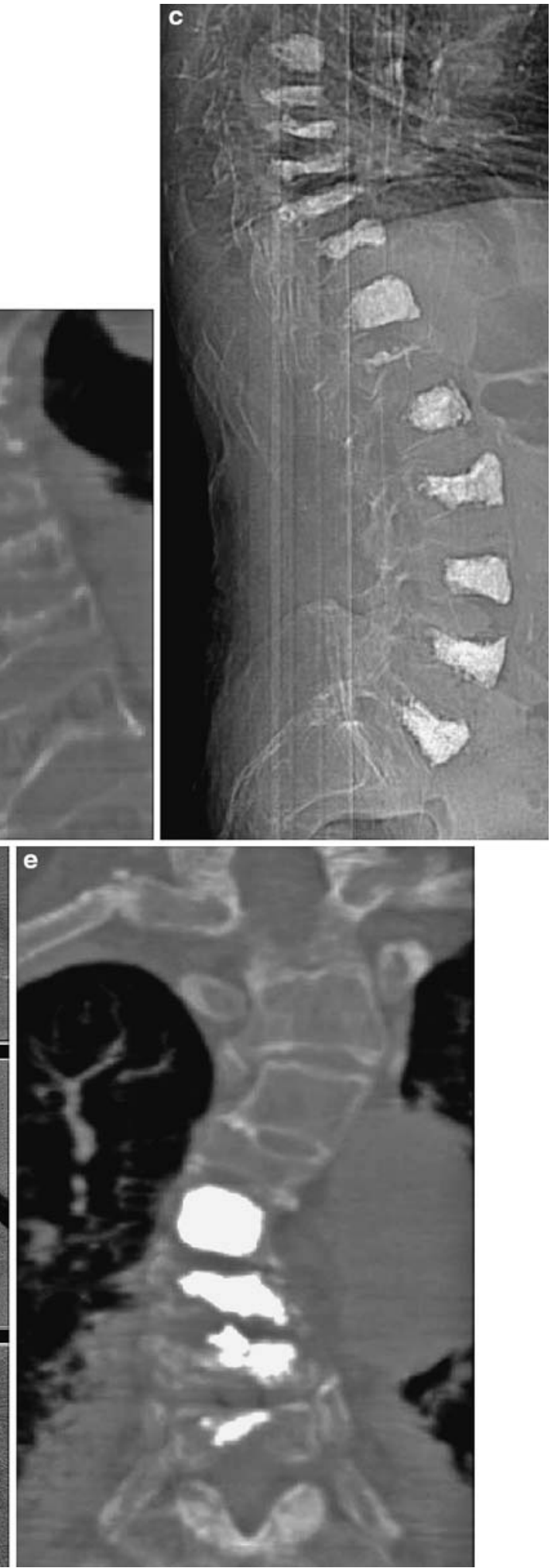
features and extrapolation of the position from adjacent vertebrae. As there was no vertebra that involved severe osteolysis of both pedicles or the vertebral cortex to a large extent, it was always possible to align the vertebral body correctly on account of the remaining osseous structures.

Excluding the patient with additional internal fixation, average operating time for patients with osteoporotic fractures was $30 \mathrm{~min}$ per level (range 13-60 min), while patients with neoplastic collapse required an average of $52 \mathrm{~min}$ (range 35-95 min) per level. The intraoperative biopsy confirmed known or suspected malignancies in all cases. The average amount of PMMA introduced per vertebrae was $2.9 \mathrm{ml}$ (range $1-5 \mathrm{ml}$ ). Blood loss was too low to be measured by conventional means and was clinically judged to be markedly less than $50 \mathrm{ml}$ in all percutaneous cases.

\section{Radiographic assessment}

Posterior vertebral body height changed from a preoperative average of $17 \mathrm{~mm}( \pm 4)$ to $18 \mathrm{~mm}( \pm 3)$ immediately postoperatively in the osteoporotic group. In the neoplastic group the change was from $15 \mathrm{~mm}$ (range: $11-18 \mathrm{~mm})$ to $16 \mathrm{~mm}(14-17 \mathrm{~mm})$. Anterior body height increased from an average of $11 \mathrm{~mm}( \pm 4)$ to $13 \mathrm{~mm}$ $( \pm 3)$ in the osteoporotic, and from $11 \mathrm{~mm}$ (range: 7$13 \mathrm{~mm}$ ) to $13 \mathrm{~mm}$ (range: $11-15 \mathrm{~mm}$ ) in the neoplastic group. Preoperative segmental kyphosis in the osteoporotic group averaged $11^{\circ}( \pm 5)$ and was reduced to an average of $9^{\circ}( \pm 4)$ postoperatively. The respective values for the neoplastic group were $7^{\circ}$ (range: $\left.0-18^{\circ}\right)$ in the preoperative and $3^{\circ}\left(\right.$ range: $\left.0-10^{\circ}\right)$ in the postoperative measurement.

\section{Complications}

Significant epidural cement leakage (estimated $0.5 \mathrm{ml}$ in the postoperative CT) occurred during the final stages of vertebral filling in one patient with unilateral osteolysis of the pedicle extending into the posterior vertebral wall (patient 9 in Table 1). As no neurological symptoms were present immediately after discontinuing anaesthesia, no further operative steps were taken and the patient

Fig. 3 Multiple fractures in a 64 year old active farmer with idiopathic osteoporosis and failed extensive conservative therapy. Treatment consisted of percutaneous kyphoplasty in two sessions (T5-T12 and L1-L5). All thoracic vertebrae were treated via the transcostovertebral approach using biplanar fluoroscopy. The preoperative CT scout (a) and sagittal (b) reconstructions of T5T9 reveal multiple vertebral collapse. Well contained PMMA placement is demonstrated in the postoperative CT scout (c), axial views of T5-L1 (d) and frontal reconstruction (e). Thoracic scoliosis is evident in the frontal CT reconstruction (e) had an uneventful recovery. Lateral perforation of the vertebral cortex occurred in another patient with an osteoporotic fracture during balloon inflation (patient 16 in Table 1). The perforation was "sealed" with a small amount of PMMA and the procedure was continued with a new batch of PMMA after the seal had cured. An estimated $1 \mathrm{ml}$ of PMMA protruded from the perforation site as a result of the seal. Minor paravertebral leakages detectable on plain radiographs were found in three other patients and leakage into an adjacent disc in three, resulting in a total leakage rate $15 \%(8$ of 55 vertebrae). No clinical symptoms were associated with any of these leakages. One patient had a superficial wound infection and another patient with disseminated cervix carcinoma metastasis suffered a perioperative deep venous thrombosis which required medical treatment (patient 18 in Table 1).

No approach related complication-especially no intraspinal perforation, intercostal nerve root irritation or pneumothorax occurred and no procedure had to be aborted.

\section{Discussion}

While the cost-benefit discussion on KP and VP has yet to be resolved and indications favouring one of the two techniques are still a matter of debate, technical aspects clearly influence the choice of procedure. While the transpedicular route has become popular for VP [9], the diameter of the KP working cannula $(4.2 \mathrm{~mm})$ is only inconsistently suitable for pedicles of the upper thoracic spine. The percentage of vertebrae with a pedicle width of less than $4.5 \mathrm{~mm}$ is given as $33 \%$ for T $4,25 \%$ for T5 and $17 \%$ for $\mathrm{T} 6$ in Caucasians [11]. These vertebrae consistently have the most slender pedicles of the thoracic spine $[11,13,15]$. In Asian populations a transpedicular route for KP may be unsuitable altogether at certain levels (average width of $\sim 4 \mathrm{~mm}$ at T4-T6 in Singaporean Chinese [13]). The strong sagittal alignment of upper thoracic pedicles and the relatively small size of the vertebral bodies further increase the difficulty of achieving sufficient tool convergence for central balloon placement through the transpedicular approach.

The transcostovertebral approach [1] allows convergent tool introduction between the posterior surface of the neck of the rib and the anterior surface of the transverse process (Fig. 1a-c). Within this bony groove the risk of injury to adjacent structures is low, nevertheless permitting the passage of tools or implants that are too large for transpedicular insertion. This principle does not only apply to KP, but has been successfully adopted in pedicle screw placement and VP. In the presented patient series, successful fluoroscopy guided balloon placement and completion of the KP procedure 

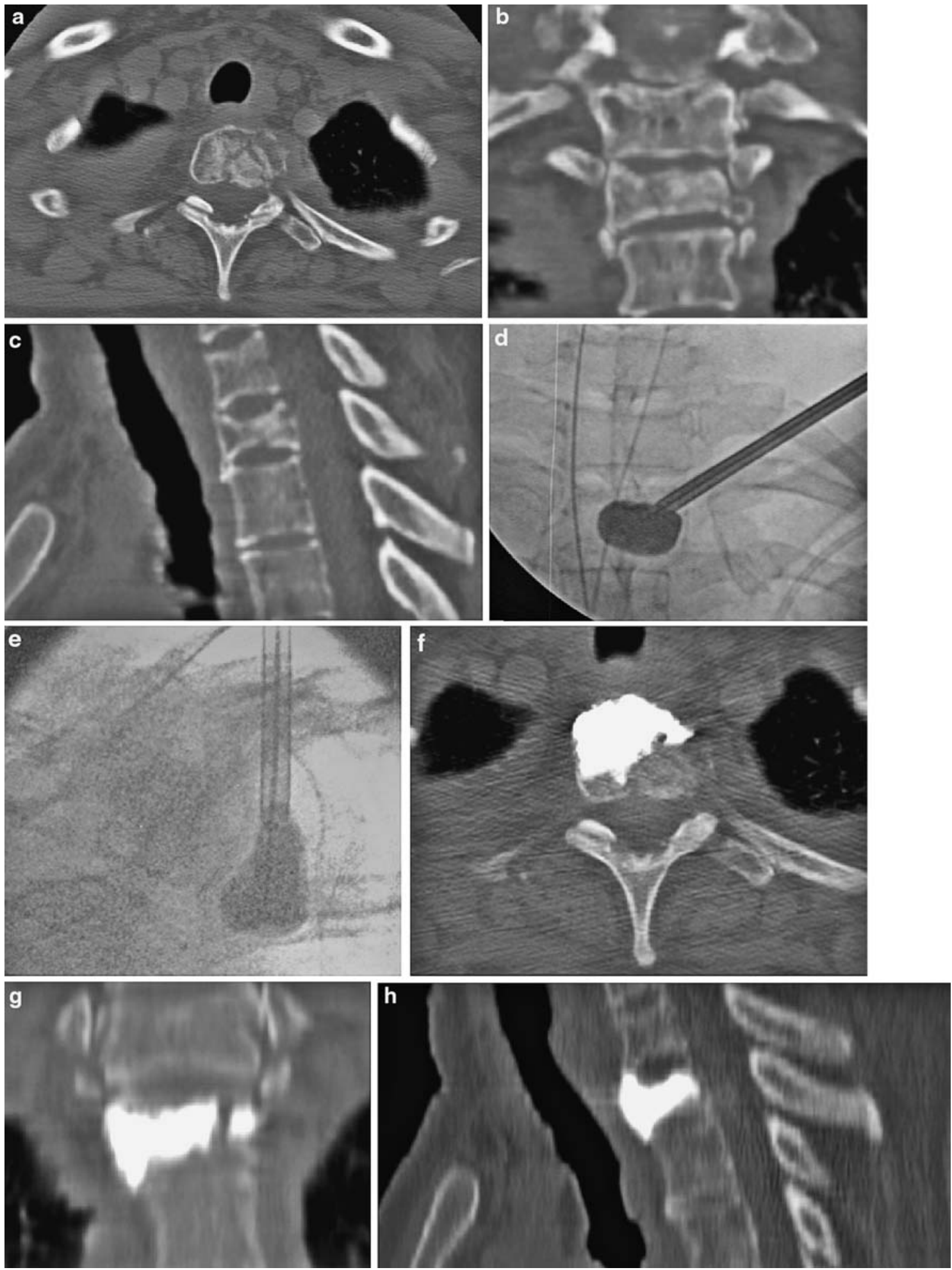

was achieved at all levels from $\mathrm{T} 2$ to $\mathrm{T} 8$ including patients with scoliosis (Fig. 3a-f) and metastatic disease (Fig. $4 \mathrm{a}-\mathrm{h})$. A slight improvement of vertebral body height (average 1-2 $\mathrm{mm}$ ) and segmental kyphosis (average $2-4^{\circ}$ ) was achieved and the overall PMMA leakage rate was low $(15 \%)$. Strict adherence to the stepwise protocol of tool introduction following the defined radioanatomical landmarks was found to be 
Fig. 4 Pathological fracture of T2 due to a cervix-carcinoma metastasis in a 52 year old patient with disseminated disease. Operative treatment consisted of unilateral, transcostovertebral kyphoplasty. Preoperative CT imaging demonstrates vertebral collapse in the axial (a), frontal (b) and sagittal (c) reconstruction. Intraoperative fluoroscopy images in the anterior-posterior (d) and lateral view (e), show central placement of the kyphoplasty balloon in the vertebral body. The projection of the posterior vertebral wall in the lateral view (e) is obscured due to superimposition of the shoulder girdle. Postoperative CT imaging in the axial (f), frontal (g) and sagittal (h) reconstruction shows PMMA to be contained within the vertebral body

mandatory for the safe completion of this minimally invasive technique. Nevertheless, the pedicle contours and posterior vertebral wall were found to pose greater visualisation difficulties in levels above T5 due to superimposition of osseous structures of the shoulder girdle.

Lateral visualisation is clearly the limiting factor of this procedure. As sufficient lateral visualisation is paramount for safe tool placement and monitoring of cement injection, a CT guided approach should be considered in the event of impossible fluoroscopic visualisation. Alternatively, an anterolateral approach to the cervicothoracic junction (C7-T3) has been described for VP in a series of nine patients [3], this approach has however not been reported for KP as yet (Fig. 4).

Acknowledgements Figures 1 and 2 were provided through courtesy of Spinegraphics.

\section{References}

1. Brugieres P, Gaston A, Heran F, Voisin MC, Marsault C (1990) Percutaneous biopsies of the thoracic spine under CT guidance: transcostovertebral approach. J Comput Assist Tomogr 14:446-448

2. Davis JW, Grove JS, Wasnich RD, Ross PD (1999) Spatial relationships between prevalent and incident spine fractures. Bone 24:261-264

3. Dufresne AC, Brunet E, Sola-Martinez MT, Rose M, Chiras J (1998) Vertébroplastie percutanée de la charnière cervico-dorsale par voie antérieure. J Neuroradiol 25:123-128

4. Evans AJ, Jensen ME, Kip KE, DeNardo AJ, Lawler GJ, Negin GA, Remley KB, Boutin SM, Dunnagan SA (2003) Vertebral compression fractures: Pain reduction and improvement in functional mobility after percutaneous polymethylmethacrylate vertebroplasty - retrospective report of 245 cases. Radiology 226:366-372
5. Fourney DR, Schomer DF, Nader R, Chlan-Fourney J, Suki D, Ahrar K, Rhines LD, Gokaslan ZL (2003) Percutaneous vertebroplasty and kyphoplasty for painful vertebral body fractures in cancer patients. $\mathbf{J}$ Neurosurg (Spine) 98:21-30

6. Garfin SR, Hansen AY, Reiley MA (2001) Kyphoplasty and vertebroplasty for the treatment of painful osteoporotic compression fractures. Spine 26:1511-1515

7. Heini P, Orler R (2004) Vertebroplastik bei hochgradiger Osteoporose. Orthopäde 33:22-29

8. Lieberman IH, Dudeney S, Reinhardt MK, Bell G (2001) Initial outcome and efficacy of "kyphoplasty" in the treatment of painful osteoporotic vertebral compression fractures. Spine 26:1631-1638

9. Lin DD, Gailloud P, Murphy KJ (2001) Percutaneous vertebroplasty in benign and malignant disease. Neurosurgery Quarterly 11:290-301

10. Magerl F, Aebi M, Gertzbein SD, Harms J, Nazarian S (1994) A comprehensive classification of thoracic and lumbar injuries. Eur Spine J 3:184-201
11. McLain RF, Ferrera L, Kabins M (2002) Pedicle morphology in the upper thoracic spine. Spine 27:2467-2471

12. Philips FM, Erling H, Campbell-Hupp M, McNally T, Wetzel FT, Gupta P (2003) Early radiographic and clinical results of balloon kyphoplasty for the treatment of osteoporotic vertebral compression fractures. Spine 28:2260-2267

13. Tan SH, Teo EC, Chua HC (2004) Quantitative three-dimensional anatomy of cervical, thoracic and lumbar vertebrae of Chinese Singaporeans. Eur Spine J 13:137-146

14. Wong W, Reiley M, Garfin S (2000) Vertebroplasty/Kyphoplasty. J Women's Imaging 2:117-124

15. Zindrick MR, Wiltse LL, Doornik A, Widell EH, Knight GW, Patwardhan AG, Thomas JC, Rothman SL, Fields BT (1987) Analysis of the morphometric characteristics of the thoracic and lumbar pedicles. Spine 12:160-166 